\title{
Correction to: A report on teaching a series of online lectures on quantum computing from CERN
}

\author{
Elías F. Combarro ${ }^{1,2}$ - Sofia Vallecorsa ${ }^{2}$ - Luis J. Rodríguez-Muñiz ${ }^{3}$ \\ Álvaro Aguilar-González ${ }^{3}$. José Ranilla ${ }^{1}$ (D) . Alberto Di Meglio ${ }^{2}$
}

Published online: 2 June 2021

(C) Springer Science+Business Media, LLC, part of Springer Nature 2021

\section{Correction to: The Journal of Supercomputing https://doi.org/10.1007/s11227-021-03847-9}

During proof correction part of the acknowledgement was missed.

The correct version is given below:

This work was supported in part by the Ministry of Economy, Industry and Competitiveness from Spain/FEDER under Grant TIN2017-87600-P, by the Regional Ministry of the Principality of Asturias under Grant FC-GRUPIN-IDI/2018/000226, and by Campus de Excelencia Internacional of the University of Oviedo in collaboration with Banco de Santander, as part of the "ayudas económicas de movilidad de excelencia para docentes e investigadores de la Universidad de Oviedo.

The original article can be found online at https://doi.org/10.1007/s11227-021-03847-9.

José Ranilla

ranilla@uniovi.es

Elías F. Combarro

efernandezca@uniovi.es

Sofia Vallecorsa

Sofa.Vallecorsa@cern.ch

Luis J. Rodríguez-Muñiz

luisj@uniovi.es

Álvaro Aguilar-González

aguilaralvaro@uniovi.es

Alberto Di Meglio

Alberto.Di.Meglio@cern.ch

1 Computer Science Department, University of Oviedo, Oviedo, Spain

2 CERN openlab, CERN, Geneva, Switzerland

3 Department of Statistics and O.R. and Math Education, University of Oviedo, Oviedo, Spain 
The original article has been corrected.

Publisher's Note Springer Nature remains neutral with regard to jurisdictional claims in published maps and institutional affiliations. 